\title{
Assessment strategies and employability in the environmental and engineering sectors
}

\author{
Debbie Bartlett ${ }^{1}$, Deborah Sims ${ }^{2}$ \\ ${ }^{1}$ Faculty of Engineering \& Science, University of Greenwich, UK, corresponding author \\ d.bartlett@greenwich.ac.uk Orcid ID 0000-0002-5125-6466 \\ ${ }^{2}$ Faculty of Engineering \& Science, University of Greenwich, UK
}

\begin{abstract}
This case study builds on material presented at the HEA Advance STEM conference held in Birmingham, England, in January 2019 which raised the issue of assessment strategies, suggesting that, for example, examinations do little to prepare students for the workplace. The initial research has been developed to provide an analysis of the current assessments in ecology/environmental management and civil engineering and the relevance to the tasks new entrants carry out in their roles as young professionals. We have developed our initial research, carried out in spring/early summer 2019, to explore this in more depth, using a survey to investigate early career professionals' perceptions of the usefulness of the various types of assessment they experienced at university and to the requirements of their jobs. At the same time, we asked the employers of graduate ecologists/environmental managers and civil engineers how well prepared they feel graduate entrants are for their job roles and whether they are finding it difficult to recruit applicants with the appropriate competency, with respect to both transferable and technical skills.

We argue that greater links and communication between employers and education providers would benefit the employability outcomes for graduates and ease the transition between university and the workplace and we make recommendations for competency-based assessment strategies.
\end{abstract}

This research was supported by the University of Greenwich Learning and Teaching Fund.

Keywords: authentic assessment; feedback; competency; employability

\section{Background}

The higher education landscape in the United Kingdom (UK) is changing. While 'employability' has long been a buzz word in academic circles, particularly with respect to curriculum development, it is surprising how few direct links there are between universities and industry. Rising fees have increased competition and prospective students are more discerning, particularly those considering an MSc in such science, technology, engineering and mathematics (STEM) subjects as ecology, environmental management and engineering, where professional body accreditation is increasingly important in giving graduates a place on the career ladder. Engineering apprenticeships are well established, with those for environmental practitioners (Level 6) and ecologists (Level 7) just coming online. This effectively places the employers, rather than the students, in the client role and, consequently, they are likely to be highly critical of programmes that do not deliver real value 
for money (Wade and Bartlett, 2017). There are worrying implications. Shayer (2019), in an article directed at landscape architects, advised employers to look beyond graduates, suggesting that many degree programmes are out of date and that other recruitment strategies have the added benefit of new entrants without the burden of student debt.

Evidence of a 'skills gap', the mismatch between the products of the (higher) education system and what employers want, is well established. Osmani et al. (2015) reviewed the attributes required by employers in the business management, accounting and computer science sectors; Bartlett and Gomez Martin (2017) focused on the skills gap in ecology and environmental management. Both studies highlighted the importance of transferable - often considered 'soft' - skills, as opposed to sector-specific technical ones. Apprenticeship standards are based on knowledge, skills and behaviours (KSBs) and professional bodies use these as the basis for evidencing competencies, the KSBs necessary to perform activities to the required standard to progress between membership grades. Mueller (2005) drew attention to the need for 'authentic assessment', to measure the knowledge and skills students have acquired during the learning process. Fook and Sidhu (2010, p.153) argued that, while the purpose of assessment is to evaluate students' performance, "institutions of higher education have to revisit their purpose of assessment if they hope to equip their learners with skills and competencies needed to succeed in today's workplace". These authors develop this theme further by suggesting that assessment should be the means of increasing and developing learning rather than merely measuring it. While this is the rationale for providing feedback and, in an ideal world, would stimulate reflection and improvement, how does assessment by examination fit in with this notion of transformative learning? Little - if any - feedback is given on exam scripts other than the final mark.

Haak (2019) reminded academics that focusing on summative assessment ignores decades of research on the ways that assessment can facilitate and enable students' learning, a perception corroborated by the systematic review of learner engagement with feedback carried out by Winstone et al. (2017). Formative feedback is a much more active approach, can enable genuine transformative learning (Lam et al., 2017; McCarthy, 2017) and is closer to workplace reality, where work is likely to go to a superior and be returned, with comments, for amendment. It is possible that academics may see this as increasing workload, although that could be alleviated by peer review and/or reduction in the overall number of assignments. Students may likewise consider formative submissions as additional work and it may be necessary to explain their direct relationship to workplace competencies, rather than merely as learning outcomes in the module descriptors - i.e., increasing assessment literacy (Carless and Boud, 2018; Haak, 2019). A recent Times Higher Education (THE) feature entitled 'Does university assessment still pass muster?' suggested that exams and essays should be replaced by assessment methods that are much closer to real-world tasks, in response to concerns about employability and student satisfaction (Mckie, 2019).

The authors of this paper combine active roles in their respective professional bodies with teaching and have introduced an increasing amount of authentic assessment in their ecology/environmental management and civil engineering modules, but this an uphill task when colleagues tend to favour traditional assessments. We designed this research to assess how useful graduates have found different types of assessment in the early stages of their professional careers, to provide an evidence base for informing future assessment 
strategies, particularly in the applied STEM areas of ecology/environmental management and engineering.

\section{Method}

While there are significant numbers of Greenwich graduates in both subject areas, we wanted a wider pool of responses. We contacted the Institute of Civil Engineers (ICE) and the Chartered Institute of Ecology and Environmental Management (CIEEM), the relevant professional bodies, and both committed to distributing simple questionnaires to graduate members to enable national circulation. In the case of CIEEM, these numbered around 850 . We decided to limit the number of questions and to keep them as simple as possible to maximise response rate - since early career ecologists and engineers are under time pressure. We offered no incentive for completion. Although we discussed the option at length, we agreed that nothing would be gained from acquiring data on gender or ethnicity. The aim was simply to find out which types of assessment had proved most useful in the workplace.

We developed two separate questionnaires, one aimed at recent graduates in the early stages of their career and the other at employers of graduates. After approval in January 2019 by the University of Greenwich Research Ethics Committee, these were piloted in February 2019 on twelve recent graduates and two employers and then put into SurveyMonkey for distribution. Timing was an issue. The questionnaires were ready in early March, but, as CIEEM were already running a survey on wellbeing in the workplace, the survey was delayed until early May, after the Easter holiday period. We publicised the employers' survey on Linkedln and ran it concurrently.

Question 1 contained a list of typical assessments generated from discussion with MSc Environmental Conservation and Civil Engineering students at the University of Greenwich; it asked respondents to indicate how useful they had found each type in preparing them for the tasks they were required to perform in their workplace.

Question 2 asked to what extent the feedback they received while at university had enabled them to improve and Question 3 asked how this had prepared them for the type of feedback they received in the workplace. The rationale for these questions was that while students are given feedback to enable them to improve in future assignments in job roles this would be with the expectation that they would respond, revising their work to the standard required for it to be signed off.

Question 4 asked respondents to identify their job role so that responses from ecologists and engineers could be differentiated.

Question 5 was open, providing an opportunity for respondents to comment freely on their university assessment experience.

We kept the employer survey questions to a minimum as we anticipated it would be difficult to get responses. The first question asked if graduate employees were adequately prepared for their job roles; the second asked for suggestions for any specific assessment tasks that could increase employability; the third asked whether recruitment focused on BSc or MSc 
graduates. We targeted personal contacts as we felt this would be the most successful way to get engagement.

\section{Results}

The results from the two surveys appear separately in the following sections.

\section{The graduate survey}

This contained five questions and received sixty-two responses with a $100 \%$ completion rate for those participating. Unfortunately, as we received only three responses from engineers, we removed these and based the analysis on the fifty-nine from the ecology/environmental management professions. Responses are provided in the following tables.

Table 1: Summary of responses to Q1 assessment tasks identified as most useful in the job role (in the order they appeared in the survey) * indicates assessments relating principally to civil engineers.

\begin{tabular}{|c|c|c|c|c|c|c|}
\hline & Very useful & Fairly useful & Useful & Neutral & $\begin{array}{c}\text { Not very } \\
\text { useful }\end{array}$ & $\begin{array}{l}\text { Not useful at } \\
\text { all }\end{array}$ \\
\hline Practical field investigations & 32 & 19 & 51 & 6 & 2 & 0 \\
\hline Presentations & 30 & 21 & 51 & 8 & 0 & 0 \\
\hline $\begin{array}{l}\text { Carrying out risk } \\
\text { assessments }\end{array}$ & 26 & 22 & 48 & 1 & 3 & 7 \\
\hline Critical review of documents & 28 & 19 & 47 & 9 & 2 & 1 \\
\hline Presenting research to peers & 19 & 28 & 47 & 11 & 1 & 0 \\
\hline Group projects & 25 & 20 & 45 & 9 & 4 & 1 \\
\hline Plant identification & 26 & 18 & 44 & 13 & 0 & 2 \\
\hline Practical tests & 21 & 23 & 44 & 11 & 3 & 1 \\
\hline Essays & 19 & 24 & 43 & 12 & 2 & 2 \\
\hline Dissertations & 20 & 22 & 42 & 8 & 7 & 2 \\
\hline Writing method statements & 21 & 21 & 42 & 9 & 4 & 4 \\
\hline $\begin{array}{l}\text { Carrying out Phase } 1 \text { Habitat } \\
\text { Survey }\end{array}$ & 23 & 18 & 41 & 11 & 5 & 2 \\
\hline $\begin{array}{l}\text { CPD portfolio to evidence } \\
\text { competency }\end{array}$ & 22 & 17 & 39 & 8 & 3 & 0 \\
\hline Site visit reports & 21 & 18 & 39 & 10 & 3 & 7 \\
\hline $\begin{array}{l}\text { Project management } \\
\text { scenarios }\end{array}$ & 22 & 16 & 38 & 10 & 6 & 5 \\
\hline Writing management plans & 23 & 15 & 38 & 10 & 6 & 5 \\
\hline $\begin{array}{l}\text { Preliminary Ecological } \\
\text { Assessment }\end{array}$ & 24 & 12 & 36 & 10 & 6 & 7 \\
\hline Lab reports & 16 & 18 & 34 & 13 & 8 & 4 \\
\hline Mock advice to clients & 16 & 18 & 34 & 9 & 5 & 11 \\
\hline Poster presentations & 13 & 20 & 33 & 14 & 9 & 3 \\
\hline Computer modelling & 7 & 22 & 29 & 17 & 7 & 6 \\
\hline Exams & 8 & 19 & 27 & 12 & 12 & 8 \\
\hline Writing business plans* & 5 & 19 & 24 & 17 & 10 & 8 \\
\hline Compiling risk registers & 10 & 12 & 22 & 20 & 6 & 11 \\
\hline $\begin{array}{l}\text { Writing contract } \\
\text { documentation* }\end{array}$ & 8 & 12 & 20 & 21 & 7 & 11 \\
\hline Videos & 5 & 11 & 16 & 25 & 9 & 9 \\
\hline Role play & 2 & 13 & 15 & 21 & 12 & 11 \\
\hline Prototypes* & 1 & 6 & 7 & 31 & 6 & 15 \\
\hline
\end{tabular}


Conversely, those considered least effective are shown in table 2, below.

Table 2: The assessment tasks identified as least useful in the job role

\begin{tabular}{|c|c|c|c|c|c|c|}
\hline & Very useful & Fairly useful & Neutral & Not very useful & $\begin{array}{l}\text { Not useful at } \\
\text { all }\end{array}$ & Not useful \\
\hline Role play & 2 & 13 & 21 & 12 & 11 & 23 \\
\hline Prototypes** & 1 & 6 & 31 & 6 & 15 & 21 \\
\hline Exams & 8 & 19 & 12 & 12 & 8 & 20 \\
\hline Videos & 5 & 11 & 25 & 9 & 9 & 18 \\
\hline Writing business plans* & 5 & 19 & 17 & 10 & 8 & 18 \\
\hline $\begin{array}{l}\text { Writing contract } \\
\text { documentation* }\end{array}$ & 8 & 12 & 21 & 7 & 11 & 18 \\
\hline Compiling risk registers & 10 & 12 & 20 & 6 & 11 & 17 \\
\hline Mock advice to clients & 16 & 18 & 9 & 5 & 11 & 16 \\
\hline Computer modelling & 7 & 22 & 17 & 7 & 6 & 13 \\
\hline $\begin{array}{l}\text { Preliminary Ecological } \\
\text { Assessment }\end{array}$ & 24 & 12 & 10 & 6 & 7 & 13 \\
\hline Lab reports & 16 & 18 & 13 & 8 & 4 & 12 \\
\hline Poster presentations & 13 & 20 & 14 & 9 & 3 & 12 \\
\hline $\begin{array}{l}\text { Project management } \\
\text { scenarios }\end{array}$ & 22 & 16 & 10 & 6 & 5 & 11 \\
\hline Writing management plans & 23 & 15 & 10 & 6 & 5 & 11 \\
\hline $\begin{array}{l}\text { Carrying out risk } \\
\text { assessments }\end{array}$ & 26 & 22 & 1 & 3 & 7 & 10 \\
\hline Site visit reports & 21 & 18 & 10 & 3 & 7 & 10 \\
\hline Dissertations & 20 & 22 & 8 & 7 & 2 & 9 \\
\hline Writing method s & 21 & 21 & 9 & 4 & 4 & 8 \\
\hline $\begin{array}{l}\text { Carrying out Phase } 1 \text { Habitat } \\
\text { Survey }\end{array}$ & 23 & 18 & 11 & 5 & 2 & 7 \\
\hline Group projects & 25 & 20 & 9 & 4 & 1 & 5 \\
\hline Essays & 19 & 24 & 12 & 2 & 2 & 4 \\
\hline Practical tests & 21 & 23 & 11 & 3 & 1 & 4 \\
\hline Critical review of documents & 28 & 19 & 9 & 2 & 1 & 3 \\
\hline $\begin{array}{l}\text { CPD portfolio to evidence } \\
\text { competency }\end{array}$ & 22 & 17 & 8 & 3 & 0 & 3 \\
\hline Plant identification & 26 & 18 & 13 & 0 & 2 & 2 \\
\hline Practical field investigations & 32 & 19 & 6 & 2 & 0 & 2 \\
\hline Presenting research to peers & 19 & 28 & 11 & 1 & 0 & 1 \\
\hline Presentations & 30 & 21 & 8 & 0 & 0 & 0 \\
\hline
\end{tabular}

Question 2 asked participants whether feedback had helped them to improve their work, with most responding that it had enabled moderate improvements (table 3 ). 
Table 3: Impact of feedback on improvement

\begin{tabular}{|l|r|r|}
\hline Did feedback enable improvement? & responses & $\%$ (rounded) \\
\hline A lot & 21 & $36 \%$ \\
\hline Moderately & 34 & $58 \%$ \\
\hline Not at all & 4 & $7 \%$ \\
\hline
\end{tabular}

Question 3 asked whether participants felt that the feedback they received as students had prepared them for their experience in the workplace. Twenty-five (42\%) felt it had, while thirty-four $(58 \%)$ felt it had not.

Question 4 was open and asked respondents to name their job role. Forty-one (69.5\%) had the word 'ecologist' in their title and most of the others included the term 'environment' or 'environmental'.

Question 5, also open, asked for comments on university assessments. These are included below, grouped into comments (verbatim) on 1) assessment and feedback in general and 2) technical/practical topics.

Table 4: Responses to open question 5 , grouped by topic

\begin{tabular}{|c|c|}
\hline \multirow[t]{13}{*}{ Assessments } & $\begin{array}{l}\text { I felt assessment grading was too rigid in terms of meeting criteria and sticking to a certain } \\
\text { format that did not allow any creativity within the content }\end{array}$ \\
\hline & $\begin{array}{l}\text { Not overly useful or reflective of real reports. But a good variety of formats, such as report, } \\
\text { presentations etc. }\end{array}$ \\
\hline & $\begin{array}{l}\text { Minority of assignments were assigned for the 'sake' of assignment, rather than thinking } \\
\text { about what practices would be useful in a professional setting }\end{array}$ \\
\hline & I would have preferred a project management course/assessment \\
\hline & Maybe too much group work \\
\hline & $\begin{array}{l}\text { Plant and animal ID tests were useful, memorising essays to write under exam conditions } \\
\text { are not useful. Essay writing and completing a mock section of an Environmental Statement } \\
\text { was useful. Field ID most useful thing. }\end{array}$ \\
\hline & They were not applied enough in their nature - too academic career focused \\
\hline & They need to be valuable for employers to see skills have been built \\
\hline & Striking the right balance between academic rigour and professional reporting is crucial \\
\hline & They were not applied enough in their nature \\
\hline & A lot of made-up scenarios, would be good to use more practical real-world examples \\
\hline & Practical work prepared me better than my exams could \\
\hline & More report writing practice would have been useful \\
\hline \multirow[t]{4}{*}{ Feedback } & Very subjective \\
\hline & $\begin{array}{l}\text { Sometimes feedback unhelpful, particularly when working at a high level but still wanting to } \\
\text { improve, the feedback generally just tended to be "very good" rather than constructive } \\
\text { improvement }\end{array}$ \\
\hline & Not very useful \\
\hline & Sometimes very late return \\
\hline \multirow[t]{4}{*}{ Content } & $\begin{array}{l}\text { It would be more useful to learn about planning and policy at university rather than focus as } \\
\text { much on practical ecology }\end{array}$ \\
\hline & Need more practical field-based oriented modules \\
\hline & Good background on legislation, lacking on protected species survey skills \\
\hline & More field identification (ID) skills would have been useful \\
\hline
\end{tabular}




\begin{tabular}{|l|l|}
\hline Other & $\begin{array}{l}\text { My masters was very challenging and helped me grow as an individual but the way I was } \\
\text { tied to one supervisor's opinion on everything made for a very difficult and stressful } \\
\text { relationship }\end{array}$ \\
\hline $\begin{array}{l}\text { My university career had sandwich placement at a botanic garden. The course was very } \\
\text { broad, entitled "ecology, evolution and behaviour" and was not necessarily intended to } \\
\text { prepare students for careers in ecological consultancy (or other) so much as to teach them } \\
\text { about current research. The placement year was the key aspect in terms of facilitating my } \\
\text { career in ecology (of which consultancy is only a small part); however, the degree was a } \\
\text { requirement for all the jobs I have applied for. }\end{array}$ \\
\hline
\end{tabular}

\section{The employer survey}

This received fourteen responses, from over thirty contacted. Four identified as in the ecology/environmental management sector and ten as engineering companies. This may be misleading as many large companies, while primarily engaged in engineering, have large ecology/environmental management divisions.

Question 1 asked whether graduate employees were able to carry out the required tasks adequately. Twelve answered yes, with two responding that they were not, although one caveated that this was unless they had taken a specialist degree and had additional work/field experience. One of the 'yes' responses added that this was not in all cases, suggesting a 'maybe' option was needed.

Question 2 asked whether there were any specific assessment tasks that could increase employability. Responses are grouped into specific technical and transferable (or 'soft') skills in table 5.

\section{Table 5: Employers' views on assessments that would improve job readiness.}

\begin{tabular}{|c|c|}
\hline \multirow[t]{8}{*}{$\begin{array}{l}\text { Technical } \\
\text { skills }\end{array}$} & $\begin{array}{l}\text { Bat surveys using professional survey kit (e.g. walkabouts, 'Echo Meter Touch' (a type of bat } \\
\text { detector); great crested newt and reptile surveys }\end{array}$ \\
\hline & $\begin{array}{l}\text { The core role of the university must remain to teach the principles of the academic field of } \\
\text { study }\end{array}$ \\
\hline & Awareness of business information modelling $(x 2)$ \\
\hline & Designing mitigation for species based on survey findings \\
\hline & Interpreting legislation \\
\hline & Understanding the National Planning Policy Framework and the policy drivers for ecology \\
\hline & Health and safety \\
\hline & Digital engineering \\
\hline \multirow[t]{5}{*}{$\begin{array}{l}\text { Transferable } \\
\text { skills }\end{array}$} & $\begin{array}{l}\text { Professionalism coaching: communication skills, asking questions, being enthusiastic, asking } \\
\text { for more experience, being present (and leaving the phone alone), updating managers on } \\
\text { progress and delivering to deadlines }\end{array}$ \\
\hline & Communication skills and project management \\
\hline & Work-private life balance - setting goals \\
\hline & $\begin{array}{l}\text { Basic office tasks - reporting back to line mangers on progress and using initiative to suggest } \\
\text { next steps after completing work. }\end{array}$ \\
\hline & $\begin{array}{l}\text { Group assessment tasks, working and being effective in collaborative groups with people } \\
\text { you do not know. }\end{array}$ \\
\hline
\end{tabular}

Question 3 asked whether graduates were employed with a BSc (one), MSc (two) or both (eleven). One who replied 'both' added that there had formerly been a preference for MSc 
candidates, but that they were increasingly finding that the best BSc graduates are as good and so more are being recruited at that level.

\section{Discussion}

While it might not seem at first glance to be entirely logical, it is the response to question 4 that frames this discussion of the results. Although the original intention was to engage with early career ecologists, environmental managers and engineers, forty-one $(69.5 \%)$ respondents had the word 'ecologist' in their job title, with most of the remainder having the term 'environment' or 'environmental' included in theirs. Only three were engineers. The results need to be considered within this context. Conversely, the employers were more mixed, with four identifying as in the ecology/environmental management sector and ten as engineering companies.

\section{The graduate survey}

The responses to question 1 showed that the assessment tasks considered most useful were the practical ones (table 1). Combining responses to practical field investigations (51), plant identification (44), practical tests (44) and Phase 1 (41) gives a total of 180 positive responses, with roughly two thirds of respondents identifying that a high proportion of their work would be field-based, particularly early in their careers. As it is usual for newly employed graduates in this field to assist initially with surveys, competency in, for example, plant identification is likely to be tested during the recruitment process. The data collected is usually passed on to more senior colleagues for processing into information and report preparation. All fieldwork requires risk assessment, something else likely to be mentioned in interviews, so it is not surprising that this was also high on the list. Presentations, including presenting research to peers, also featured high in the ranking, generally agreed to involve key communication skills and, again, likely to be useful in job interviews and so valuable components of employability. Critical review of documents was ranked fourth and combines research skills, critical thinking, and concise writing, all valuable attributes in the workplace. However, group projects, sixth in the combined ranking, was a surprise as these are unpopular with students and often lead to disagreements about allocation of workload and unfair marking. It would be gratifying to think that this is the result of maturity, with the realisation that teamwork, getting along with other people, sharing skills, and collaborating towards a common goal all form a valuable part of the student journey.

The top six in the least favoured assessments (table 2) are, in the main, tasks that would be more relevant to engineers than ecologists and environmental managers. The fact that role play was deemed the least useful is perhaps no surprise, as again this is something students tend to dislike and feel awkward about. Competency comprises knowledge, skills and behaviours; therefore, arguably, an element of role play could be an advantage in the workplace, though perhaps not at the early career stage surveyed for this research. Prototype-based assessments, ranking second, would be relevant only to engineers, as would compiling risk registers (7). It was not a surprise to find exams at number 3 . Writing business plans and contract documentation, ranking 5 and 6 respectively, are more likely to be used as assessment for engineers, with management plans probably the ecology/environmental management equivalent, but junior staff would, no doubt, not be involved. It was surprising to us that portfolios - which we use to evidence competency, 
indexed against the CIEEM Competency Framework (CIEEM 2019) - did not rank more highly, as these are popular and highly useful in interviews and to supplement curricula vitae to secure employment. Maybe this assessment method is not common in other universities (nine respondents left this blank). In retrospect, for clarification, we should have included an additional question, asking which assessment types had been experienced, or a 'not applicable' option. Alternatively, while portfolios may have value at the job application and interview stage, they may not be useful once in employment. One participant mentioned that commercial and business awareness was very useful for their current job role; perhaps this should be included in the professional studies modules that seem to be replacing research methods in applied subjects.

Perceptions of assessment tasks that demonstrated transferable skills, particularly communication, tended to contrast with the view voiced by Martini (2019) that students do not always recognise the importance of transferable skills, such as communication. It would have been interesting to see if there was a difference in perception here, between students and early career professionals. It may be that the value of assessment tasks becomes apparent only when these are used in the workplace.

An additional question could, in retrospect, have been included, asking which types of assessment respondents had experienced during their university studies. This would have added a further dimension to the analysis. The importance of there being an appropriate range of assessments was discussed by Evans (2013) and is particularly important for students on vocational programmes, particularly MScs that lead directly into specific careers.

Question 2 related to feedback on assessments asking whether this had enabled improvement. The response was a lukewarm positive with the majority $(\sim 58 \%)$ responding that it was moderately helpful. Additional comments on this were made in response to the open question 5 (see table 4 in the results) highlighting the need for feedback to be timely, useful and constructive. These reflect the well-established dichotomy between the vague assessment of learning, demonstrated by the unhelpful 'very good', and the type of feedback and assessment for learning where the comments made by the tutor - ideally - facilitate development (Fook and Sidhu, 2010), while it is likely that respondents came from many different UK universities that, without doubt, have differing assessment and feedback strategies. However, constructive and timely feedback on assessment is central to the ' 10 Guiding Principles' of the QAA Expectations and Practices for Assessment (2018) and it would be expected that all higher education institutions (HEls) would working within this context. Question 3 asked how well participants felt that the feedback they received as students had prepared them for the type of feedback they had experienced in the workplace. The results showed a relatively even distribution, with twenty-five (42\%) feeling it had while thirty-four (58\%) felt it had not. This is a particularly interesting topic and may reflect the extent to which formative assessment is used across the sector. In the workplace, graduates will produce work that is submitted to their line manager for comment, probably to be returned for amendment and re-submission before approval. For students, submitting formatives tends to be voluntary, with outlines or 'work in progress' being the basis for feedback that can, on this basis, be only rather general, as opposed to the more detailed and so more constructive - response that can be given on full drafts. Assessment deadlines are often, of necessity, towards the end of modules and this fact, combined with the habit of some to leave work till the last minute, militates against using formatives in the 
most productive way for learning. This student behaviour may also reflect a short fall in assessment literacy and genuine realisation of the value of interim comments aimed to improve the final submission and so the mark. We have seen good results in the Environmental Law and Policy module, by asking students to give a presentation on which they receive feedback from tutors and peers, which can then be incorporated into their final summative - report. This is not referred to as a formative, but the method and rationale are explained early in the module, effectively developing assessment literacy. As administrative burdens on staff are tending to increase, this may seem to create additional marking, but it may also serve to spread the marking load more evenly. Students' responses have demonstrated that they appreciate this approach and it can have a positive impact on employability, not least by increasing confidence.

Question 5 was open. The responses are given in table 4 in the results section, grouped into the topics of assessment, feedback, content and 'other'. Most comments on assessment support the idea of more practical and/or more authentic tasks, based on real-world examples. While practical tests might not exactly fit into the category of authentic assessment - on the basis that these would not really be a task carried out in the workplace - these were highlighted as particularly useful. However, these might well be a component of the interview process for junior ecologist positions and so could be considered as authentic learning to enhance employability (Ornellas et al., 2019). A particularly interesting comment related to evidencing skills: "They need to be valuable for employers to see skills have been builf". This was corroborated by other comments, such as: "Not overly useful or reflective of real reports"; "....... rather than thinking about what practices would be useful in a professional setting"; "They were not applied enough in their nature"; "would be good to use more practical real-world examples".

Fewer comments were made on feedback, but those received suggested it could be improved. Retrospectively, a question exploring the extent to which formative assessment was practised would have provided further insight. Other comments related to programme content, with two wanting more field skills, though another suggested that there should be less focus on this and more on planning and policy.

It must be remembered that, while about two thirds of respondents were early career (or junior) ecologists, the remainder identified as belonging to the wider, more varied 'environmental' category. Universities offer programmes across the spectrum, from those specialising in survey techniques to those focusing on environmental impact assessment and environmental planning and monitoring. No programme could possibly cover everything and the most successful strategy for student satisfaction may be to identify a niche, with a likely career projection and to communicate this clearly to potential students. In every case, the balance between academic rigour and professional relevance is crucial, as pointed out by one of the respondents to the open question.

\section{The employer survey}

Question 1 asked whether graduate employees were able to carry out the required tasks adequately. Twelve answered that they were (one adding that this was not true in all cases), two that they were not (one adding the caveat 'unless they had a specialist degree and/or additional work/ field experience'). It is important here to remember that all employees would 
have successfully completed a selection process, so these responses are not necessarily indicative of the competency of applicants for graduate positions. The earlier CIEEM Skills Gap project revealed that employers, commenting on applicants, required better plant identification and transferable skills, particularly project management and communication (Bartlett and Gomez Martin, 2017).

Question 2 asked whether there were any specific assessment tasks that could be useful for increasing employability. There was a surprising number of transferable skills mentioned, including communication (twice) and the ability to meet deadlines - surely inherent in university education. Again, this reflects the findings of the earlier CIEEM Skills Gap project (Bartlett and Gomez Martin, op.cit.). The extent to which students understand the purpose of assessments and are aware of the transferable skills that they are developing and demonstrating has been questioned (Martini, 2019). Perhaps the relevance of these to employability needs to be made explicit. The degree apprenticeship standards are based on knowledge, skills and behaviours and, arguably, it is the 'softer' elements, the skills and behaviours, that secure positions, as all candidates will have a degree that evidences basic knowledge. While it was not surprising that employers wanted skills, together with familiarity with equipment and standard techniques, it was perhaps more informative that many referred to behaviours. Examples, extracted from table 5, included asking questions, being enthusiastic, asking for more experience, being present (and "leaving the phone alone"), work-private life balance, setting goals, reporting back to line managers on progress, using initiative to suggest next steps after completing work and being effective in collaborative groups with people you do not know. These would apply equally across the breath of the sector and, remembering the employer respondents were biased towards engineering, not just to ecologists and environmental managers.

Question 3 asked whether graduates were employed with a BSc (one), an MSc (two) or a mixture of both (eleven). One who replied 'both' added that formerly candidates with an MSc had been preferred but increasingly the best BSc graduates are as good and so more are now being recruited. CIEEM accreditation, introduced six years ago, has now been achieved by ten BSc and seven MSc programmes, which may account for the rise in standards.

\section{Implications}

Professional bodies such as CIEEM use competencies, each defined as a combination of knowledge, skills and behaviours (or KSBs), as the criteria for membership and for progression between the career grades. These are also the basis for degree apprenticeship standards, developed in collaboration with employers, with the aim of providing the competencies required by the industry. This research demonstrates that while universities are traditionally specialists in knowledge development, graduates and employers, when considering assessment tasks, are placing a greater value on those that demonstrate skills and so contribute to evidencing competency. The important 'hidden' element is that knowledge underlies - and is a prerequisite for - the skill; for example, the ability to identify plants is based on knowledge of the differences between them.

Perhaps the most interesting dimension relates to behaviours. Apprenticeship standards give a more equal weighting to the KSBs than is apparent in university assessment. While meeting deadlines is essential throughout, expecting students to demonstrate a professional demeanour is not. Professional bodies have codes of conduct and professional standards, 
but unless teaching staff are members, they may not have easy access to these documents, nor to the relevant competency framework. Fundamental to developing an authentic assessment strategy to improve employability outcomes for students is the extent to which staff are aware of industry needs and the very rapid changes experienced in the environmental sector. This can be an additional burden on time and some programmes alleviate this by setting up an advisory group to inform the curriculum. Bringing outside speakers is another route to raising student awareness of industry expectations and how these differ from university ones.

\section{Limitations}

This research suffered from time constraints. While it had been hoped to issue the survey in early spring and hold focus groups before the busy summer survey season began, this was not possible. The response rate was disappointing. It was mailed to around 850 graduate members of CIEEM generating fifty-nine responses ( 15\%). The timing was not ideal, as the frantic summer ecological survey season begins in April/May with junior staff working long hours doing great crested newt and bat surveys at night, as well as day work. The constraints of the funding, requiring research to be completed by July, gave no choice regarding timing; we would have preferred to run the survey during the winter, when ecologists are less busy, and this is something that others working in this area might do well to bear in mind. We have no explanation for the lack of engagement from engineers, although responses were generated from employers of this group as well as those from the ecology/environmental management sector.

Despite these shortcomings, the findings provide support for 'authentic assessment' and strengthen the argument for a move towards tasks that are focused on enabling students to evidence competency. However, it can be difficult to advocate for change within the context of academia, where administrative structures designed to ensure the quality of learning and teaching tend to stifle innovation. It is often easier to continue with the same 'tried and true' practices rather than to change, even when the benefit is evident. Furthermore, not all academics have direct workplace experience. Closer links with employers and with graduates as they develop in their careers could raise awareness of the rapid changes in the workplace and expectations of graduates - and of what is needed from HEls, particularly as more degree apprenticeships become available.

The responses to all the questions are likely to have been influenced by the respondents' job roles. While an ecologist will find basic practical skills most useful, environmental managers are more likely to be engaged in research, analysis, and both written and verbal communication. As ecologists develop their careers, they are likely to use a combination of technical and transferable skills, so different responses might have resulted had the survey extended beyond the graduate career grade.

\section{Conclusion and recommendations}

This is a highly topical area of research and, despite the issues of survey timing and the lack of uptake by engineering graduates, it has produced interesting results. It seems clear that there is an appetite among both students and employers for more authentic assessment and feedback, requiring a move away from traditional essays and exams to tasks that combine academic evaluation while evidencing competency to prospective employers. The change of 
emphasis from assessment of learning to assessment for learning, well established in the literature, is particularly important in the increasingly competitive marketplace, where apprenticeships mean that employers are the clients rather than the students.

For this to happen, we recommend that:

- programmes are supported by an advisory group of employers who can identify the tasks they require graduates to be able to perform and advise on appropriate assessment to develop the required KSBs;

- quality assurance requirements are flexible enough to enable more realistic assessments to be set;

- the intended learning outcomes, included in module descriptors, make the links between KSBs and the purpose of assessments clear, particularly evidencing transferable skills;

- authentic feedback strategies, as well as those for authentic assessment, are promoted and adopted for applied STEM subjects.

There are many examples of good practice in this area and, while in the first instance it might seem to be additional work for already overloaded staff, surely the outcomes for students from genuinely work-integrated learning are worth a little extra effort?

To conclude, there is a saying: 'If you want a better answer, ask a better question. To ask our students better questions, we need to work closely with employers to ensure we are producing graduates with the competencies they need to address the industry skills gap. The next phase of this research will be to hold focus groups with both graduates and employers to explore these issues in more depth.

\section{Reference list}

Bartlett, D. and Gomez-Martin, E. (2017) 'CIEEM Skills Gap Project.' In Practice, 96, 45-47. Available at: https://gala.gre.ac.uk/id/eprint/17465/ (Accessed: 2/6/2021).

Carless, D. and Boud, D. (2018) 'The Development of Student Feedback Literacy.' Assessment \& Evaluation in Higher Education, 43(8), 1315-1325. Available at: https://doi.org/10.1080/02602938.2018.1463354 (Accessed: 2/6/2021)

CIEEM (2019) The Competency Framework. Available at: https://cieem.net/resource/competency-framework-high-res/ (Accessed: 2/6/2021).

Evans, C. (2013) 'Making Sense of Assessment Feedback in Higher Education.' Review of Educational Research, 83(1), 70-120. Available at: https://doi.org/10.3102\%2F0034654312474350 (Accessed: 2/6/21). 
Fook, C.Y. and Sidhu, G.K. (2010) 'Authentic Assessment and Pedagogical Strategies in Higher Education.' Journal of Social Sciences, 6(2), 153-161. Available at: https://DOI\#10.3844/jssp.2010.153.161 (Accessed: 2/6/21).

Haak, R. (2019) 'Let's ensure students get the best value from assessment.' Article published on Wonke, part of the Conversations on Learning series 17 June 2019. Available at: https://wonkhe.com/blogs/lets-ensure-students-get-the-best-value-fromassessment/?utm medium=email\&utm campaign=Wonkhe\%20Mondays $\% 20$ $\% 2017 \% 20$ June\&utm content=Wonkhe\%20Mondays\%20\%2017\%20June+CID 26e7db0389abc410701458b7c05a49c0\&utm source=Email\%20mark eting\%20software\&utm term=asks\%20how\%20students\%20can\%20get\%20the\%20best $\% 2$ 0value\%20from\%20assessment (Accessed: 22/2/21).

Lam, B.H., Cheng, R.W. and Yang, M. (2017) 'Formative Feedback as a Global Facilitator: Impact on Intrinsic and Extrinsic Motivation and Positive Affect.' In: Kong, S., Wong, T. and Yang M. (eds.) Emerging practices in scholarship of learning and teaching in a digital era. Singapore Springer ISBN: 9789811033445, 9789811033421, 9811033420

Chow, C. and Tse, K. (eds.) (Year date) Emerging Practices in Scholarship of Learning and Teaching in a Digital Era. Singapore: Springer. Available at:

https://doi.org/10.1007/978-981-10-3344-5 17 (Accessed: 22/2/21).

Martini, T. (2019) 'Why can't students recognise transferable skills?' Available at: https://www.timeshighereducation.com/features/why-cant-students-recognise-transferableskills (Accessed: 15/3/21).

McCarthy, J. (2017) 'Enhancing feedback in higher education: Students' attitudes towards online and in-class formative assessment feedback models.' Active Learning in Higher Education. Available at: https://doi.org/10.1177/1469787417707615 (Accessed: 15/3/21).

Mckie, A. (2019) 'Does university assessment still pass muster?' Available at: https://www.timeshighereducation.com/features/does-university-assessment-still-passmuster (Accessed: 15/2/21).

Mueller, J. (2005) 'The authentic assessment toolbox: Enhancing student learning through online faculty development.' Journal of Online Learning and Teaching, 1, 1-7. Available at: http://jolt.merlot.org/documents/vol1 no1 mueller 001.pdf (Accessed: 14/3/21

Ornellas, A., Falkner, K. and Edman Stålbrandt, E. (2019) 'Enhancing graduates' employability skills through authentic learning approaches.' Higher Education, Skills and Work-Based Learning, 9(1), 107-120. Available at: https://doi.org/10.1108/HESWBL-042018-0049 (Accessed: 15/3/21).

Osmani, M., Weerakkody, V., Hindi, V.M., Al-Esmail, R., Eldabi, T., Kapoor, K. and Irani, Z. (2015) 'Identifying the trends and impact of graduate attributes on employability: a literature review.' Tertiary Education and Management, 21(4). Available at: https://doi.org/10.1080/13583883.2015.1114139 (Accessed: 14/3/21). 
QAA (2018) 'UK Quality Code, Advice and Guidance: Assessment.' Available at:

https://www.qaa.ac.uk/quality-code/advice-and-guidance/assessment (Accessed: 15/3/21).

Shayer, M. (2019) 'How can we reap the rewards of thinking smaller?' Landscape, 2, 22-23. Available at: https://issuu.com/landscape-

institute/docs/landscape_journal_2019_2_human_skil (Accessed: 2/6/21).

Wade, M. and Bartlett, D. (2017) 'Level 7 Apprenticeships on the Horizon: are you ready to embrace them?' In Practice. 98, 46-47. ISSN 0263-841X (Print), 2042-7689 (Online)

Available at: https://gala.gre.ac.uk/id/eprint/18317/(Accessed: 2/6/21).

Winstone, N.E., Nash, R.A., Parker, M. and Rowntree, J. (2017) 'Supporting Learners' Agentic Engagement with Feedback: a Systematic Review and a Taxonomy of Recipience Processes.' Educational Psychologist, 52(1), 17-37. Available at:

https://doi.org/10.1080/00461520.2016.1207538(Accessed: 12/3/21). 